That the particle "A" could so easily be observed while under the giant magnet made the generally increasing response easy to assess; but the result was the same in the case of " $B$," which could not be observed and yet was successfully removed.

One must conclude that however poor the initial response, it is unwise to abandon the giant magnet for small magnetic intra-ocular foreign bodies until a very prolonged trial has been made. Ophthalmoscopic observation during application of the magnet is of great assistance, as the excursion obtained may increase gradually although the resting position may remain the same for a long period. Even if observation is impossible, persistence may succeed, though it is much more difficult to decide whether progress is being made.

It is not claimed that the final result in this case will be a first class eye, but it is suggested that less damage was inflicted than would have resulted from employment of the posterior route.

The patient has been seen two weeks after his discharge; the vision of the left eye had improved to $6 / 9$ with correction.

I wish to thank Mr. Maurice Whiting, F.R.C.S., and Surgeon 'Rear Admiral H. Whiteside, R.N., for their permission to report this case.

\title{
ANNOTATION
}

\section{Insidious Cases of Glaucoma}

If one thinks of the number of cataract extractions performed each year one must admit that the sequel of raised intra-ocular pressure is not very common. But it does occur sometimes and the sort of case we have in mind would be an admirable test for a candidate in an examination for a higher diploma in ophthalmology, one which, if properly investigated, would give ample opportunity for the examinee to prove his worth. For such cases are not simple cataracts or simple glaucomas; they partake of each and the signs, particularly those on the glaucomatous side, are apt to be anomalous. When one sees a patient with a highly congested eye and steamy cornea that can be seen from a distance it is usually a fairly simple matter. But with a quiet eye and clear cornea the presence of raised tension is not so obvious and the mind may easily get sidetracked into looking for other reasons for defective vision, such as lens capsule, macular change and what not. We call to mind a case of this sort which came to us from a remote part of the country 
which we should certainly have missed had not the local Aesculäpius, in a covering letter, said that on one of his visits he thought that the eye was harder than it should have been. The patient had undergone cataract extraction, and had been subsequently needled at least three times. He was really suffering from secondary glaucoma. When we saw him he had very little field left. It is not easy to be wise at all times and in all places. How often when patients make an appointment does one hear them say; "I won't keep you a moment"? If one takes their momentary statement at its face value one may find when he arrives that one is in for at least half-an-hour's work before he can be got rid of. 'With the need for keeping other appointments there is a real danger that some part of the routine examination may be-scamped. Such a thing happened once to a surgeon of our acquaintance. The patient was in a hurry and was fitted in at the last moment. He said his sight had "gone funny" in the train and wanted to be assured that there was nothing wrong. The surgeon found nothing amiss, though the examination of the fundus was not easy, as the patient was very intolerant of bright light. A week or two later he had a recurrence of his symptoms. When asked how his sight had gone funny, he answered, "I saw a coloured ring round a light in the carriage on my way home." Had our friend only persisted in enquiries as to what the patient had observed he would never have missed the chronic glaucoma present.

\section{ABSTRACTS}

\section{I--THERAPEUTICS AND OPERATIONS}

(1) Mckee, S. Hanford (Montreal). - Gonorrhoeal ophthalmia neonatorum treated with sulphanilamide. Canadian Med. Assoc. Jl., August, 1939.

(1) McKee reports a case of ophthalmia neonatorum in an infant two weeks old. The disease had started on the second or third day following birth. Each eye was affected with profuse discharge and films made from it showed the Gram-negative coffeebean shaped diplococci. The child was admitted to hospital and in addition to the usual local treatment was given daily $2 \mathrm{gr}$, of sulphanilamide every four hours in 5 doses. The weight of the infant was 8lb. Rapid improvement took place; on the fourth day the discharge had practically ceased and the infant was discharged 